\title{
DISCURSO POÉTICO Y DISCURSOS DEL PODER EN SALMOS DE ERNESTO CARDENAL
}

\author{
Alberto Rivera Vaca
}

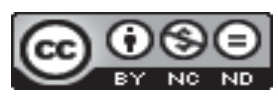

Esta obra está bajo una licencia Creative Commons

Reconocimiento-No Comercial-Sin Obra Derivada 



\title{
DISCURSO POÉTICO Y DISCURSOS DEL PODER EN SALMOS DE ERNESTO CARDENAL
}

\author{
POETIC DISCOURSE AND DISCOURSES OF POWER IN SALMOS \\ OF ERNESTO CARDENAL
}

\author{
Alberto Rivera Vaca
}

\begin{abstract}
RESUMEN
Este artículo demuestra la manera en que Salmos (1964) de Ernesto Cardenal (1925) contiene una inexorable crítica a cinco décadas del siglo XX donde a pesar del progreso científico la sociedad se embarcó a la barbarie de las guerras mundiales y la Guerra Fría. Este periodo histórico tiene una relación intrínseca con el uso manipulador de la propaganda política, bélica y comercial de los poderes hegemónicos difundidos a través de los modernos medios de comunicación masivos. Según Salmos, la propaganda contiene los discursos retóricos de los poderes hegemónicos que desvirtúan el sentido del lenguaje demostrando así la degradación y frivolidad de la vida moderna. Cardenal contrapone a la propaganda la poesía exteriorista, poesía expresada mediante una comunicación clara, objetiva y significativa. Y concluye en la fugacidad del poder, en la permanencia de la poesía, y en la necesidad de reevaluar el lenguaje del poder y el lenguaje que utilizamos para describir la realidad. Esta investigación recurre al análisis de la enunciación discursiva y al pensamiento hispanoamericano de la primera mitad del siglo XX como el de Mariano Picón-Salas y Fausto Reinaga.

Palabras clave: Poesía hispanoamericana, poesía exteriorista, Occidente, propaganda, medios de comunicación masivos.
\end{abstract}

\begin{abstract}
This article demonstrates how Salmos (1964) by Ernesto Cardenal (1925) contains an inexorable critique of five decades of the twentieth century where despite scientific progress society embarked on the barbarism of world wars and the Cold War. This historical period has an intrinsic relation to the manipulative use of the political, warlike and commercial propaganda of the hegemonic powers which is spread through the modern media of mass communication. According to Salmos, propaganda contains the rhetorical discourses of hegemonic powers that detract from the sense of language, thus demonstrating the degradation and frivolity of modern life. Cardenal opposes propaganda with exteriorist poetry, poetry expressed through clear, objective and meaningful communication. Moreover, he concludes in the transience of power, in the permanence of poetry, and in the need to re-evaluate the language of power and the language that we use to describe reality. This research uses the analysis of the discursive enunciation and the Hispanic American thought of the first half of the twentieth century such as Mariano Picón-Salas and Fausto Reinaga. Key words: Latin American Poetry, exteriorist poetry, West, propaganda, mass media.
\end{abstract}

Dr. Alberto Rivera Vaca. State University of New York. Profesor del Departamento de Idiomas y Culturas y del Departamento de Historia. Estados Unidos.

Correo electrónico: riverava@fredonia.edu

Recepción: 21- 06- 2017

Aceptación: 05- 09- 2017 
La crítica ha explicado ampliamente el contexto histórico y cultural nicaragüense y centroamericano en el momento de la producción poética de Ernesto Cardenal (Henighan, 2016; Uriarte, 2000). Otros estudios han descrito las referencias históricas de la región y los procedimientos intertextuales de la poesía cardenaliana (Durán, 2010; Lee, 2004; Daydí-Toson, 2000 y otros). En el caso de Salmos, la crítica ha señalado acertadamente las conexiones entre los salmos del Antiguo Testamento y los salmos de Cardenal en relación con los sufrimientos de la sociedad contemporánea (Bihler, 2010; Chen Sham, 2007; Borgeson, 1984; Daly de Troconis, 1982; Dapaz Strout, 1975). Debido a su importancia, Salmos requiere todavía un estudio que profundice la comprensión de la relación de estos poemas con el contexto histórico internacional de la primera mitad del siglo XX. Si bien Cardenal escribía sus salmos mientras Nicaragua vivía bajo la dictadura somocista, Salmos se integra a un contexto más amplio que el nicaragüense o centroamericano. Salmos contiene una inexorable crítica a cinco décadas del siglo XX donde a pesar del progreso científico la sociedad se embarcó a la barbarie de las guerras mundiales y la Guerra Fría. El referente de Salmos tiene una relación explícita con Europa y occidente y una relación implícita, sin disminuir su importancia, a un contexto nicaragüense y por extensión al resto de América. De esta manera, la poesía de Cardenal continúa con la posición crítica que distinguió a la generación previa de pensadores hispanoamericanos desilusionada con la civilización europea debido a la catástrofe de las grandes guerras.

Para corroborar lo dicho, primeramente analizaré la instancia discursiva de Salmos para verificar la heterogeneidad de la instancia de enunciación y del sujeto poético. Luego, demostraré que en Salmos la violencia política y bélica tiene una relación intrínseca al uso manipulador de la propaganda política, bélica y comercial de los poderes hegemónicos difundidos a través de los modernos medios de comunicación masivos. Según Salmos, la propaganda contiene los discursos retóricos de los poderes hegemónicos que desvirtúan el sentido del lenguaje demostrando así la degradación y frivolidad de la vida moderna. Cardenal contrapone a la propaganda la poesía exteriorista, poesía expresada mediante una comunicación clara, objetiva y significativa. Y concluye en la fugacidad del poder, en la permanencia de la poesía, y en la necesidad de reevaluar el lenguaje del poder y el lenguaje que utilizamos para describir la realidad. Esta investigación recurre al análisis de la enunciación discursiva de Benveniste (1999) y al pensamiento hispanoamericano de la primera mitad del siglo XX como el del venezolano Mariano Picón-Salas (1901-1965), el boliviano Fausto Reinaga (1906-1994) o el mexicano Leopoldo Zea (1912-2004). Además, considera importante una perspectiva histórica del rol de la propaganda según Corella Torres (2005), Díez Arroyo (1998) y Pizarroso Quintero (1993).

\section{Instancia de enunciación heterogénea}

Cardenal conoció ampliamente el salterio bíblico al leer, traducir y cantar salmos bíblicos mientras estudiaba en el monasterio trapense Our Lady of Gethsemani en Kentucky, entre 1957 y 1959, y en otros monasterios en Colombia y México. Escritos entre 1961 y 1964, publicó sus propios salmos en Colombia en 1964 (Mañú Iragui, 1990, p. 37). Siguiendo una similar estructura y temática, los veinticinco poemas de Salmos parafrasean salmos bíblicos. Cardenal no escribió "un Salmo para cada uno de los originales” (Borgeson, 1979, p. 379), tan solo escogió veinticinco salmos bíblicos para no repetir el contenido y para tratar temas 
colectivos y no individuales (Daly de Troconis, 1982, p. 30). Según Dapaz Strout, Cardenal retoma un texto pre-cristiano como modelo para luchar contra la injusticia, pues los autores de los salmos bíblicos tuvieron "un gran sentido de su responsabilidad histórica y social... vivieron en un mundo de castigos salvajes, de masacre, de violencia, y protestaron contra la intolerancia, la injusticia social y la corrupción moral” (1975, p. 113). Con Salmos, Cardenal se convierte en "un profeta que despierta la conciencia dormida de sus contemporáneos” (Dapaz Strout, 1975, p. 113).

Los poemas de Salmos manifiestan características de lo que se ha llamado poesía conversacional, " la cual "tiende a ser grave", "tiende a afirmarse en sus creencias, que en algunos casos son políticas y en otros religiosas, o ambas" y que "es crítica del pasado" (Fernández Retamar, 1995, p. 174). Por otro lado, en la poesía conversacional, la presencia de múltiples voces y la combinación de estas logran "una transformación del sujeto poético" (Lastra, 1987, p. 134), un "ensanchamiento y complejización de la instancia enunciadora” y una elaboración de un texto polifónico (Cornejo Polar, 1990, p. 205).

Los poemas de Salmos manifiestan estas características de la poesía conversacional explicadas. A continuación, además de ejemplificar la transformación del factor persona (sujeto poético), explicaré la heterogeneidad de los factores de lugar y tiempo de la instancia de enunciación en los poemas. ${ }^{2}$ El yo de la enunciación de Salmos no se identifica con un nombre ni este describe explícitamente características propias. Lo que se puede conocer del sujeto lírico se basa en la relación que tiene con los tres destinatarios de su mensaje. Dios es el destinatario principal de catorce poemas. Varios títulos expresan el clamor del yo poético a su receptor para ser escuchado: "Óyeme porque te invoco", "Escucha mi protesta", "Oye Señor mi causa justa”, etc. El yo poético enuncia íntimas plegarias religiosas de libertad y justicia. Otros títulos declaran "Líbrame Señor", "Libértanos tú”, "Hazme justicia Señor”, etc. Dios está presente en cada poema, ya sea como destinatario o como referente. Según Chen Sham, siguiendo las categorías de Wolfgan Kayser, este tipo de interpelación a Dios en Salmos se relaciona con el apóstrofe lírico (Chen Sham, 2007, p. 23). Pero además, el yo poético se dirige a la gente común que sufre injusticias (ver Salmos 11 y 36), y cuando no les habla directamente a estas personas, siempre hace alguna alusión a las mismas. Asimismo, el yo poético se dirige directa o indirectamente a los líderes mundiales (ver Salmos 5, 11, 48). Algunos de estos destinatarios son líderes de gobiernos represores, gobernantes con poder bélico atómico, acaudalados, famosos, etc. Por tanto, en Salmos, la figura literaria del apóstrofe lírico se dirige no solamente a Dios, sino a múltiples destinatarios. Incluso, en algunos poemas, el yo poético interpela simultáneamente a varios de los destinatarios mencionados.

Chen Sham realiza una descripción de Salmos siguiendo las características del discurso religioso de los salmos bíblicos y la condición religiosa de Cardenal, enfoque que muestra otros rasgos del yo poético de Salmos. Basado en Orar con los salmos (1979) de Mariana Mannati, Chen Sham explica Salmos a través de una perspectiva escatológica. Según Chen Sham, el tono y la actitud de los poemas son de súplica y de acción de gracias mediante la plegaria. La súplica se basa en la convicción del poeta de una intervención divina ante las injusticias; y la acción de gracias manifiesta el testimonio del poder divino (Chen Sham, 2007, pp. 22-23). De esta manera, la modernización de los salmos bíblicos logra "renovar y de actualizar el enfoque cristiano de la salvación del hombre" (Chen Sham, 2007, p. 22).

El yo poético del texto, representa asimismo una voz colectiva. Se dirige a Dios en la primera persona del plural: "Y nosotros/ tu pueblo/ te alabaremos eternamente/ y te cantaremos de generación/ en generación" (Cardenal, 1969, p. 78). Este sujeto lírico se 
considera parte de una comunidad que experimenta situaciones adversas. Desde su clamor personal expresa además el sentir colectivo. Es la voz de los presos que aboga ante Dios, denuncia a los opresores, y une su voz al clamor de la sociedad. Asimismo, en algunos poemas de Salmos, el sujeto poético intercala el uso de la primera persona del singular y del plural: “Ten piedad de mí Señor porque estoy en tribulación/ Mientras ellos están en fiesta/ - están brindando - / lloramos en la noche/ en la casa saqueada/ Estamos de luto en la mesa de comer" (Cardenal, 1969, p. 35, ver también el Salmo 15). Al expresarse en primera persona del singular o del plural, se asemeja a la oración religiosa personal cuando un sujeto ora a solas; o cuando un sujeto ora en la primera persona del plural expresando los deseos y sentimientos del resto de las personas que lo acompañan.

El lugar y el tiempo de la enunciación de varios poemas se sitúan principalmente en Europa, durante las décadas de los años 30 y 40, en el contexto de la Segunda Guerra Mundial. Abundan las referencias explícitas como campo de concentración (Salmos 16,43, 113), cámara de gas (Salmos 21 y 43), producción de guerra (Salmo 5), etc. Asimismo hay menciones a las armas atómicas (Salmos 4, 148) y la radioactividad (Salmo 19). Con respecto al 'aquí' del enunciado, el verso sitúa constantemente a este 'yo' en un "campo de concentración”. De hecho, en varios poemas, el sujeto lírico enuncia desde aquel lugar: "Mírame Señor en el campo de concentración/ Con alambradas!” (Cardenal, 1969, p. 17).

En Salmos, los factores 'ahora' y 'aquí' de la instancia de la enunciación son heterogéneos. Debido a la representación colectiva que incorpora este hablante lírico, el 'aquí' del enunciado poético se diversifica: "Desde lo profundo clamo a ti Señor!/ Clamo de noche en la prisión/ y en el campo de concentración/ En la cámara de torturas/ en la hora de las tinieblas/ oye mi voz/ mi S.O.S" (Cardenal, 1969, p. 59). El yo poético se expresa desde múltiples lugares del campo de concentración, desde "lo profundo" hasta otros ambientes de aquel lugar de reclusión y tortura. El poema establece así diversos espacios desde donde el sujeto poético enuncia.

Pero este factor del lugar de la instancia de enunciación se hace aún más complejo. El Salmo 21 comienza: "Dios mío, Dios mío ¿por qué me has abandonado?/ ... / Me rodean los tanques blindados/ estoy apuntado por las ametralladoras/ y cercado de alambradas/ las alambradas electrizadas/ Todo el día me pasan lista/ ... / Me han llevado desnudo a la cámara de gas" (Cardenal, 1969, p. 31). En estos primeros versos, todavía existe un 'aquí' identificado con los distintos ambientes de un campo de concentración. ${ }^{3}$ El hablante lírico del texto se encuentra rodeado de elementos represivos y de control. Más aún, el yo poético se dirige camino a la muerte en las cámaras de gas. El yo poético se desplaza y enuncia desde múltiples lugares.

Todavía cabe señalar que este yo lírico se expresa por otros sujetos, y el factor del lugar de la instancia de enunciación se hace heterogéneo. El poema citado continúa: "grito con la camisa de fuerza/ grito toda la noche en el asilo de enfermos mentales/ en la sala de enfermos incurables/ en el ala de enfermos contagiosos 4 en el asilo de ancianos/ agonizo bañado de sudor en la clínica del psiquiatra/ me ahogo en la cámara de oxígeno/ lloro en la estación de policía/ en el patio de presidio/ en la cámara de torturas/ en el orfelinato/ estoy contaminado de radioactividad/ y nadie se me acerca para no contagiarse" (Cardenal, 1969, pp. 31-32). Este sujeto poético representa la voz de desequilibrados mentales, enfermos, ancianos, presos, torturados, huérfanos, etc. Por lo tanto, no solamente el 'yo' y el 'aquí' se diversifican, sino además el 'ahora' de la enunciación. 
En el poema se pueden identificar acontecimientos ocurridos en distintos momentos durante la Segunda Guerra Mundial: la reclusión en los campos de concentración, activos durante varios años incluso antes de la guerra; el bombardeo atómico sobre las ciudades japonesas de Hiroshima y Nagasaki en 1945 y la consecuente carrera armamentística atómica. Los demás lugares nombrados en el poema (manicomio, hospicio, orfanato, etc.) pueden pertenecer tanto al periodo del Tercer Reich como a algún momento anterior o posterior al mismo. La instancia del enunciado poético trasciende a una determinación temporal y espacial.

Por tanto, no obstante los poemas refieren al periodo de las grandes guerras mundiales, tratan implícitamente a otras regiones del mundo y otras épocas históricas. Salmos es una voz para todo el mundo, se dirige a todos los habitantes: "Óiganme todos los pueblos/ Escuchad todos vosotros habitantes del mundo/ plebeyos y nobles/ los proletarios y los millonarios/ todas las clases sociales" (Cardenal, 1969, p. 45). Para Borgeson, el yo poético "extiende el mensaje sálmico a todos los pueblos oprimidos de hoy". Y una de las características más creativas con un efecto estilístico valioso es la "pluralidad de hablantes" que "trascienden los tiempos y lugares específicos, y la poetización se funda en la universalidad de la opresión” (1984, p. 58).

\section{Desilusión: ciencia y barbarie}

La composición de poemas basados en los salmos bíblicos es un "subgénero de la poesía lírica" de larga data. Durante el siglo XX, este tipo de poemas expresan "la evolución de la sociedad y de la cultura moderna y las grandes catástrofes surgidas hasta mediados de este siglo, incluso la de la explosión de la primera bomba atómica... produjeron un cambio sensible" en este subgénero (Bihler, 2010, 193). En 1945, cuando finalizó la Segunda Guerra Mundial, Cardenal era un joven poeta de veinte años. Publicó Salmos en 1964, a sus treinta y nueve años, casi dos décadas después de la conclusión de la guerra, en plena Guerra Fría.

Como describí anteriormente, la mayor parte de las referencias históricas de los salmos de Cardenal tratan de los sufrimientos de las personas durante la Segunda Guerra Mundial bajo la persecución y la reclusión en los campos de concentración nazis. Igualmente, Salmos menciona lo sucedido durante la Guerra Fría (Valle-Castillo, 2010, p. 33), periodo donde las grandes potencias mundiales medían sus fuerzas para imponer sus influencias y formas de vida. Debido a la heterogénea instancia de enunciación de los poemas, explicada anteriormente, veo que Cardenal expresa en Salmos de 1964 una severa crítica a por lo menos 50 años de ciencia y barbarie en Europa (1914-1964), época plagada por la violencia de las Guerras Mundiales (1914-1945) y al enfrentamiento entre Occidente y Oriente durante la Guerra Fría (1947-1964). Así como la Primera Guerra Mundial "es una guerra que viene a resolver contradicciones del siglo anterior" (Pizarroso Quintero, 1993, p. 226), "la segunda guerra mundial fue una consecuencia directa de los problemas irresueltos por la primera" (Pizarroso Quintero, 1993, p. 392).

Esta visión crítica de Cardenal con respecto a Europa es una continuación del pensamiento crítico de la primera generación intelectual de América latina del siglo XX. Para 1930: "La primera generación latinoamericana del siglo XX inauguró el desencanto y el escepticismo respecto de la cultura de Europa" (Rivera-Rodas, 2010, p. 17). Los jóvenes hispanoamericanos de aquella generación de pensadores habían sido críticos de los resultados del progreso de la civilización europea debido a las secuelas de las guerras que provocaron. Por ejemplo, el venezolano Mariano Picón-Salas (1901-1965) dijo que el periodo de 1930 y 1950 fue "una época de "malos salvajes" en la que trenes modernos conducían gente velozmente a 
las cámaras de gas donde les esperaban profesores de química: "Una época tan orgullosa de su exactitud tecnocrática tenía que inventariarles el pelo y los huesos... Europa estaba devorando, a dentelladas, su propia cultura" (1962, p. 35). Las decenas de millones de muertos y las atrocidades que experimentó la sociedad durante aquellas décadas no tienen parangón en la historia moderna de la humanidad.

Picón-Salas extiende su crítica al resto de Europa y no solo a la Alemania Nazi, pues dijo en otra oportunidad:

\begin{abstract}
La enfermedad del espíritu europeo fue el orgullo, de un intelectualismo divorciado de la vida y tan altaneramente jerárquico, que engendró como reacción el resentimiento de masas enormes sin esperanza y sin destino. Toda la ciencia alemana, sus centenares de filósofos y millares de profesores universitarios fueron incapaces de detener el cáncer invasor del nazismo (1947, p. 235)
\end{abstract}

El pensador boliviano Fausto Reinaga (1906-1994), perteneciente a la misma generación de Picón-Salaz, fue uno de los pensadores más acérrimos del intelectualismo europeo basado en la razón y la ciencia. Con respecto a la razón, Reinaga dijo: "Esta pobre 'diosa' es el demiurgo, motor y brújula del absolutismo, la democracia, la revolución, el nazismo, el fascismo, el marxismo y la Bomba Atómica" (1978, p. 206). Esta crítica a Europa la hizo extensiva a otras regiones y épocas: "La razón son las dos guerras Mundiales. La razón es Hiroshima y Nagasaki, es el Vietnam, el Medio Oriente, es Angola y Líbano; es Chile, es Argentina” (1978, p. 157). En su obra, Reinaga expresa constantemente la urgencia de abandonar el camino que Europa había trazado para el resto del mundo.

Salmos no menciona la palabra "Nicaragua" ni hace referencias explícitas a la historia de este país ni a la dictadura de Somoza con excepción de la sigla "GN" en el Salmo 7 que designa obviamente a la Guardia Nacional de Somoza (Henighan, 2016, p. 85). Debido a la heterogénea instancia de enunciación, la temática de Salmos se hace extensiva mediante alusiones indirectas a la situación que experimentó Nicaragua durante la dictadura de los somozas desde 1936 en el contexto de las Guerras Mundiales y la Guerra Fría. Asimismo, estos poemas se ocupan implícitamente a la situación de varios países del resto de América durante aquellas décadas donde se establecieron prolongadas dictaduras que reprimieron y torturaron. La poesía de Cardenal resuena en el lector hispanoamericano debido a su experiencia bajo dictaduras militares (Shaw, 2008, p. 57). Por varias décadas, Salmos tuvo una gran recepción en la sociedad hispanoamericanas, pues refería a situaciones políticas que la gente padecería aún después de la publicación del volumen en 1964, pues varias dictaduras establecieron campos de concentración como la de Alfredo Strossner (1954-1989) en Paraguay, la de Augusto Pinochet (1973-1990) en Chile o las juntas militares (1976-1982) en Argentina.

En Salmos, Cardenal continúa la reflexión crítica de pensadores hispanoamericanos que le precedieron, generación desencantada con Europa debido a la barbarie de sus guerras a pesar del progreso de su ciencia. Cardenal también medita la circunstancia histórica posterior a estas guerras que le tocó vivir. Y como se verá a continuación, Cardenal censura el discurso de los grupos hegemónicos transmitido por la propaganda política y la propaganda de guerra, ambas directamente relacionadas con la tecnificación de la propaganda comercial, la cual inculca hábitos de la vida moderna de Occidente. Por Occidente se entiende lo que el filósofo mexicano Leopoldo Zea (1912-2004) dijo en 1955:

llamo mundo occidental u Occidente al conjunto de pueblos que en Europa y en América, concretamente los Estados Unidos de Norteamérica, han realizado los ideales culturales y materiales de la Modernidad que se hicieron patentes a partir del siglo XVI. Realización que dio, por un lado, origen a los sistemas democráticos liberales y, por el otro, al industrialismo con su sistema de expansionismo económico sobre el mundo no Occidental (1955, p. 8) 
Posteriormente Zea dijo: "El capitalismo, esto es, el mundo occidental" (1957, p. 80). ${ }^{5} \mathrm{Al}$ considerar esto, se verá a continuación la manera en que los salmos de Cardenal no condenan simplemente la violencia de la guerra o la dictadura sino que la relaciona con un sistema político y económico.

\section{Discursos del poder: propaganda y medios de comunicación en Salmos}

Corella Torres explica que la "propaganda es instrumento de la política", "es el manejo de la comunicación con fines de poder” (2005, p. 53). La propaganda política y de guerra existe desde la antigüedad, pero tiene un rol esencial en el desarrollo histórico del siglo XX (Pizarroso Quintero, 1993, pp. 25 y 225). La propaganda de guerra es "la continuación de la propaganda política" (1993, p. 34). Luego de la Primera Guerra Mundial acontece "una gran preparación teórica que permite abordar la propaganda de guerra en gran escala desde nuevas perspectivas" (1993, p. 393). Por ejemplo, en Propaganda Technique in the World War de 1927, el estadounidense Harold D. Lasswell ya había concluido que "la propaganda es uno de los más poderosos instrumentos en el mundo moderno" (Citado en Pizarroso Quintero, 1993, p. 37). Para la Segunda Guerra Mundial: "La radio, desde los años veinte, y el cine sonoro, desde los treinta, suponen una revolución en los medios de comunicación. La prensa sufrirá también cambios importantes" (Pizarroso Quintero, 1993, p. 285).

Más de la mitad de los veinticinco poemas de Salmos menciona los términos eslogan y propaganda, y refiere continuamente a los medios de comunicación. El Salmo 16 asevera: "Escucha mi oración que no son slogans/ ... / Yo no repito lo que dicen los radios de los hombres/ ni su propaganda comercial/ ni su propaganda política/ Yo guardé tus palabras/ y no sus consignas" (1969, p. 25). El eslogan es una fórmula breve y original utilizada para la propaganda comercial y la propaganda política. Pero la guerra engendró el término, pues se originó del gaélico escocés, y era un grito de guerra para reunir a los miembros de un clan. El uso del eslogan en la propaganda de guerra es propio del siglo XX. En la Primera Guerra Mundial, el imperio británico utilizó el eslogan "tu país te necesita" para reclutar soldados; y dos años después surgió otro eslogan semejante en los Estados Unidos: "el ejército te necesita". En el contexto de la Revolución Rusa, los eslóganes como "tierra, pan y paz" o "todo el poder para los soviets" fueron comunes. Ya para 1930, el partido nazi había utilizado el eslogan “¡Alemania despierta!” aún antes de controlar el gobierno. Este último eslogan "Se hizo tan familiar en estandartes y en manifestaciones, en periódicos y en radiodifusiones, que se convirtió en un saludo tan habitual como "buenos días"' (Corella Torres, 2005, p. 91). La ascendencia del nazismo en Alemania y el fanatismo que produjo entre los alemanes se debieron a varios factores, pero por sobre todo al manejo de la propaganda (Corella Torres, 2005, pp. 10-11). ${ }^{6} \mathrm{Si}$ bien varios de los poemas de Salmos se refieren a la propaganda nazi, se aplican de igual modo a la propaganda de guerra en general.

En Salmos, los términos 'eslogan' y 'propaganda' son sinónimos de la palabra 'mentira'. El yo lírico expresa: "Sus palabras son pura propaganda/ Y no hablan sino slogans" (Cardenal, 1969, p. 49). Estos versos están constituidos con base en expresiones coloquiales como "sus palabras son pura mentira" o sus palabras "no hablan sino mentiras". Cardenal reemplaza ciertas expresiones o lemas coloquiales como "Dominaremos con la verdad" o "La verdad está con nosotros" de la siguiente manera: "Dominaremos con la Propaganda/ La Propaganda está con nosotros" (Cardenal, 1969, p. 21). 
En Salmos la propaganda política y de guerra estimula la violencia: “...la JUSTICIA es un slogan!/ Sus Declaraciones de Prensa son falsedad y engaño/ Sus palabras un arma de propaganda/ un instrumento de opresión" (Cardenal, 1969, p. 19). Y el Salmo 34 afirma: "Su propaganda no es de paz/ Tú oyes sus radios/ Están provocando la guerra/ tú ves sus televisiones/ no calles!/ Despierta" (Cardenal, 1969, p. 39). La propaganda además incita al desprecio: "Su propaganda se ríe de nosotros/ y nos caricaturizan" (Cardenal, 1969, p. 39); "La propaganda se burla de nosotros/ y slogans de odio nos rodean (Cardenal, 1969, p. 47); "Sus ametralladoras están emplazadas contra nosotros/ y los slogans de odio nos rodean" (Cardenal, 1969, p. 26).

Cardenal denuncia en Salmos la ausencia de ética tanto a nivel del lenguaje como en el orden del comportamiento de los grupos dominantes de poder, los cuales encubren sus auténticas intenciones y acciones mediante un lenguaje ambiguo y manipulador. En el Salmo 5, el poeta acusa a los líderes de países poderosos: "Hablan de paz en sus discursos mientras aumentan su producción de guerra/ Hablan de paz en sus Conferencias de Paz/ y en secreto se preparan para la guerra" (Cardenal, 1969, p. 13). Existe entonces una ausencia de integridad, una falta de correlación entre el pensamiento, el discurso y el accionar.

Una característica fundamental de la propaganda es la repetición. El yo poético alerta de las consecuencias de estar expuestos repetidamente a la propaganda. Cardenal advierte en Salmos: "Sus radios mentirosos rugen toda la noche" (Cardenal, 1969, p. 13). El sujeto lírico además se pregunta angustiado: “Hasta cuándo hablarán sus radios?” (Cardenal, 1969, p. 16). La repetición es tan absoluta que el yo poético afirma: "estoy contaminado de radioactividad" (Cardenal, 1969, p. 32), aludiendo a la exposición de las repeticiones que emiten las radios a semejanza de la radiación atómica. Debido a esto el desafío para la sociedad consiste en protegerse de la repetición de estos ya que coloca a las personas en una situación pasiva al convertirse simplemente en receptoras de aquellos mensajes.

Así como el eslogan es empleado durante la guerra, también es empleado en la propaganda comercial, la cual recurre extensivamente a la ambigüedad (Díez Arroyo, 1998, p. 80) apelando a menudo al eslogan por su brevedad y originalidad. Al referirse a la repetición de la propaganda comercial, Cardenal dice: "Bienaventurado el hombre que no lee los anuncios comerciales/ ni escucha sus radios/ ni cree en sus eslogans" (Cardenal, 1969, p. 9). En varios poemas el sujeto poético de Salmos se niega a escuchar o repetir la propaganda comercial debido al lenguaje engañoso que utiliza. Los poemas advierten de su peligro y por eso el yo poético insiste: "No escuchamos sus programas/ ni creemos sus anuncios/ No nos vestimos con sus modas/ ni compramos sus productos/ No somos socios de sus clubs/ ni comemos en sus restaurantes" (Cardenal, 1969, p. 23).

La repetición de la propaganda produce ansiedad en los receptores. El yo lírico dice: "No te impacientes si los ves hacer muchos millones/ ... / No envidies a los millonarios/ ni a las estrellas de cine/ a los que figuran a ocho columnas en los diarios/ a los que viven en hoteles lujosos/ y comen en lujosos restaurantes" (Cardenal, 1969, p. 39). La envidia o la impaciencia por imitar estas representaciones amplificadas es una forma contraria a la libertad. No escuchar la propaganda significa liberarse emocionalmente de las supuestas insatisfacciones de la vida moderna, permitiendo la liberación de la voluntad del individuo. La propaganda comercial puede mostrar una realidad frívola a través del lenguaje y el contenido que propaga: "Lo que se consume son 'significados', y este consumo no tiene límite. El sistema de valores de nuestra sociedad (hedonista y narcisista, que alimenta la llama individual frente a la masificación) es lo que incita al consumo. La publicidad, el discurso del consumo, vende belleza, éxito, juventud, 
distinción, admiración" (Díez Arroyo, 1998, p. 109). De ahí que Cardenal dice: "Yo no rindo culto a las estrellas de cine/ ni a los líderes políticos/ y no adoro dictadores/ No estamos suscritos a sus periódicos/ ni inscritos en sus partidos/ ni hablamos con slogans ni seguimos sus consignas" (Cardenal, 1969, p. 23). El anglicismo "slogan" utilizado en los poemas en lugar de su par en castellano representa a la actual vida moderna influenciada por el consumismo y la publicidad. Con respecto a los términos en inglés en otros poemas de Cardenal - lo cual se puede aplicar a Salmos - Borgeson asevera que "evocan la esterilidad de una vida moderna" (1984, p. 95). Esto no es simplemente un reproche a un sistema socioeconómico, continúa Borgeson, sino a la crisis de la sociedad entera: "Los anglicismos, en escala mayor, son una manera concisa y eficaz de evocar nada menos que una crisis de proporciones mundiales" (1984, p. 95).

Cardenal contrapone su discurso poético a los discursos de los poderes hegemónicos basados en la propaganda. En Salmos, el yo poético clama por la libertad de la voluntad y el pensamiento, además de la libertad física de la cárcel y los campos de concentración. Por eso advierte del peligro de escuchar constantemente la propaganda del poder. Cuando Cardenal habla de acallar las radios y no escuchar la propaganda ni los eslóganes, lo hace pensando en la libertad del individuo ante la intensa influencia de los discursos engañosos del poder. El mensaje engañoso de la propaganda, contenido que aparenta ser racional, influye en el aspecto emocional del receptor para manipular su opinión. Una vez que el individuo actúa según los propósitos del emisor, asume voluntariamente un tipo de dependencia. Cardenal advierte sobre esta falta de libertad, la pérdida del control de las emociones, del ejercicio de la voluntad y el pensamiento.

Al estudiar la propaganda política, Corella Torres explica que esta opera sobre las emociones simples o complejas que las personas experimentan (2005, p. 73). Y concluye: "Todos los sentimientos humanos e instintos han proporcionado a los propagandistas la posibilidad de influenciar a los sujetos receptores, apelando a ellos" (2005, p. 74). Pizarroso Quintero dice más aún: "la propaganda es un acto de violencia mental para forzar a alguien a someterse a nuestra voluntad" (1993, p. 34). Y afirma: "Una vez que el mensaje ha llegado a la audiencia se pone en marcha el mecanismo de la unanimidad o contagio." (1993, p. 36). De ahí que el yo poético de Salmos pide protección a Dios de los mensajes de los discursos del poder: "Libértanos tú/ porque no nos libertarán sus partidos/ Se engañan los unos a los otros/ Y se explotan los unos a los otros/ Sus mentiras son repetidas por mil radios/ sus calumnias están en todos los periódicos" (Cardenal, 1969, p. 21).

En Salmos, Cardenal no separa la conexión entre la propaganda política y de guerra de la propaganda comercial. Esto se debe a que la propaganda política y comercial tienen una relación estrecha en cuanto a la técnica de sus procedimientos: "la propaganda política es ampliamente deudora de la publicidad comercial en cuanto a sus técnicas", y de este modo, "las técnicas de la publicidad comercial se han adueñado de la propaganda política en Occidente" (Pizarroso Quintero, 1993, p. 429). De modo que a diferencia de la comunicación o conversación personal entre dos o más personas mediante un canal de comunicación común como la escritura o el habla, según Salmos, los grupos de poder utilizan canales de comunicación sofisticados para difundir su propaganda: "Sus Mentiras son repetidas por mil radios/ Sus calumnias están en todos los periódicos/ Tienen oficinas especiales para hacer Mentiras" (Cardenal, 1969, p. 21). Los versos aluden a la tecnología desarrollada en las primeras décadas del siglo XX. Corella Torres menciona que el perfeccionamiento de la propaganda nazi tiene relación estrecha con la época de avances tecnológicos (2005, p. 26). En Salmos, la comunicación altamente sofisticada y artificiosa, producto de los avances 
científicos, se contrapone a la comunicación interpersonal natural. Los medios masivos de comunicación repiten constantemente los mensajes de los grupos de poder para lograr que las formulaciones no solo sean persuasivas sino que puedan ser igualmente memorizables. ${ }^{7}$ El poeta declara: "Nos insultan en los radios toda la noche/ y los técnicos se reúnen de noche contra nosotros/ elaborando planes perfectos" (Cardenal, 1969, p. 36). La perfección de la "propaganda científica, sistemáticamente organizada, es un producto" exclusivo del siglo XX (Pizarroso Quintero, 1993, p. 45).

El invento de la radio, el cine y la televisión fueron productos extraordinarios de la ciencia de las primeras décadas del siglo XX. Con respecto a la sofisticación técnica de los medios masivos de comunicación, Pizarroso Quintero explica: "En el mundo occidental el desarrollo económico y el enorme desarrollo de los medios de comunicación de masas harán de la publicidad comercial no sólo un fenómeno cotidiano, emblemático de nuestras sociedades, sino un terreno en el que se perfeccionarán día a día las técnicas de persuasión de masas" (1993, p. 226). Consecuentemente, como lo señalé antes, Cardenal expresa en Salmos aquello que la generación hispanoamericana previa había denunciado: la enfermedad del espíritu de Europa, el orgullo, según el venezolano Mariano Picón-Salas, el avance técnico de la ciencia separado de la vida, el orgullo de la exactitud que corroyó la cultura europea. O como dijera el boliviano Fausto Reinaga, Europa hizo de la razón una pobre 'diosa' impulsora de catástrofes. Por consiguiente: "El hombre europeo, al exigir la dictadura de la razón, se ha convertido en objeto de funestos vasallajes, recubiertos, en parte, con ropajes deslumbrantes. Cargado de ciencia y de técnica, ha vuelto a un estado parecido al de la esclavitud" (Kogon, 2005, p. 19). Por todo lo dicho, Cardenal opone al lenguaje de la propaganda de técnica sofisticada, la poesía exteriorista de expresión objetiva como se verá a continuación.

\section{Permanencia de la poesía: exteriorismo y verdad}

Todo Salmos tiene una relación intertextual apegada a los salmos bíblicos, Cardenal emplea ideas surgidas hace siglos y las actualiza en el siglo XX sin abandonar la alusión al pasado. Los salmos bíblicos tienen un componente artístico, son oraciones religiosas que pueden ser cantadas o recitadas, pues eran compuestos generalmente para ser acompañados por un instrumento como el salterio, instrumento musical de cuerdas semejante a la cítara. Igualmente, en Salmos, los poemas de Cardenal son plegarias destinadas a Dios en forma de canto: "Pero yo te cantaré a ti porque eres justo/ te cantaré en mis salmos/ en mis poemas" (Cardenal, 1969, p. 15). Para este poeta, escribir poesía forma parte de su expresión religiosa: "Te cantaré en mis poemas/ toda mi vida" (Cardenal, 1969, p. 38). Poesía y alabanza están vinculadas: "Cantaré al Señor mientras yo viva/ le escribiré salmos" (Cardenal, 1969, p. 56). ${ }^{8}$ Tanto la oración y la poesía son una expresión intensa de vivir su religiosidad y un medio para expresar sus preocupaciones sociales. En este sentido, como asevera Chen Sham, los salmos de cardenal poseen una expresión hímnica singular ya que tienen "la modalidad del himno de alabanza" (Chen Sham, 2007, p. 22). Salmos como el 148 y 150 llegarán a ser "verdaderos cantos de alabanza" (Chen Sham, 2007, p. 28; Chen Sham, 2016, p. 132).

Mediante el yo poético Cardenal explica la naturaleza de las palabras con que compone sus salmos: "En ti Señor confío/ no sea jamás confundido/ ... / Tú me has libertado oh Señor/ Dios de la verdad/ ... / Que callen para siempre sus radios mentirosos" (Cardenal, 1969, pp. 35-36). Las palabras de este Dios de la verdad son "limpias/ y no de Propaganda" 
(Cardenal, 1969, p. 21), y el yo poético las sigue o "guarda" (Cardenal, 1969, p. 24). Del mismo modo, el yo poético indica que se expresa con "proverbios" y "sabias palabras" (Cardenal, 1969, p. 45). Por lo cual dice: "Escucha mi oración que no son slogans / Júzgame tú/ ... / no hallarás en mí ningún crimen" (Cardenal, 1969, p. 25). Para Cardenal, las palabras de sus salmos o poemas aspiran ser limpias, trasparentes y comprensibles; sin engaño, sin eslogan. Al escribir con "sabias palabras" describe su propia poesía como colmada de sinceridad, veracidad y exactitud.

Es así que Cardenal utiliza en su poesía las nociones de "verdad" y "falsedad". Por ejemplo, a lo largo de toda su obra poética y desde una perspectiva histórica, Cardenal habla de la verdad en el contenido del lenguaje y denuncia la falsedad de los discursos de poder en la historia de América. En El estrecho dudoso mediante la voz de Bernal Díaz del Castillo, Cardenal dice: "Porque el agraciado componer es decir la verdad" (1971, p. 141). En Homenaje a los indios americanos, a través de la voz de un maya, acusa al discurso colonial de haber mentido: "Palabras falsas han llovido sobre nosotros/ ... / Palabras falsas. Palabras de locura" (1972b, p. 58). En Epigramas Cardenal incrimina a los gobiernos contemporáneos: "Le saquean al pueblo su lenguaje./ Y falsifican las palabras del pueblo" (1972a, p. 55).

La noción de la verdad es una característica fundamental en el discurso poético de Cardenal. A mi entender, esta verdad se relaciona con algunas características de la poesía exteriorista, siendo Cardenal el exponente principal de la misma. ${ }^{9}$ Cardenal ha explicado que el exteriorismo es la poesía del "mundo que vemos y palpamos", "la poesía objetiva: narrativa y anecdótica, hecha con los elementos de la vida real y con cosas concretas, con nombres propios y detalles precisos y datos exactos y cifras y hechos y dichos" (1975, p. VII-VIII). Por consiguiente, Cardenal ha señalado que durante las dictaduras no es tiempo "de atacar a los gorilas con poemas surrealistas" (1978, p. 296). Y pregunta: “¿Y para qué metáforas si la esclavitud no es metáfora/ ni es metáfora la muerte en el Rio das Mortes/ ni lo es el Escuadrón de la Muerte?" (1978, pp. 295-296). Cardenal ha afirmado: "No me gusta la poesía del disparate ni los hermetismos, surrealismos y dadaismos. Mi poesía es una poesía clara y que se entiende" (Citado en Borgeson, 1984, p. 91). Según Veiravd, el lenguaje exteriorista de Cardenal busca información objetiva y verificable: utiliza comillas para repetir mensajes o citar fragmentos de textos verificables; menciona nombres propios que no admiten ambigüedad, etc. Por esto el exteriorismo de Cardenal utiliza un lenguaje que enfatiza la función referencial (Veiravd, 1975, pp. 81-88).

Para Cardenal, esta objetividad del lenguaje y la mención a elementos concretos de la realidad de la poesía exteriorista, ha existido desde la antigüedad. La poesía bíblica es una poesía exteriorista, ya que, junto a otras, es "lo que ha constituido la gran poesía de todos los tiempos" (2008, p. 13). Tanto en Salmos como en el resto de su obra poética, la verdad debe considerarse como el proceso continuo para la comprensión objetiva de la realidad a través de los elementos concretos de la vida. La verdad en la poesía de Cardenal, es la indagación y la adquisición de conocimiento, proceso cognitivo mediatizado por el lenguaje, el cual requiere, como lo explicaré en un momento, la revaluación constante de las palabras con las que se describen la realidad. Asimismo, esta aproximación objetiva a la realidad exige expresiones claras, significados unívocos para comunicarla. Respecto a la "verdad" en la poesía de Cardenal, Daly de Troconis afirma: "Lo verdadero es lo exacto, en tanto que es fiel a la realidad y en ese sentido es concreto" (1982, p. 19). Por consiguiente, Cardenal asume una responsabilidad con su poesía: "El poeta es también, entonces, el guardián de esa palabra verdadera, para 
impedir que sea convertida en algo abstracto" (Daly de Troconis, 1982, p. 19). Razón por la cual en Salmos - este discurso poético basado en la verdad o poética de la verdad- se contrapone a los discursos engañosos del poder político, comercial, etc., elaborados mediante la manipulación del lenguaje para la persuasión de los receptores.

Cardenal opone a los reiterativos procedimientos de la propaganda la perdurabilidad de la poesía, pues ha dicho: "Creo que la poesía es más duradera que otra clase de mensaje. Por eso busco decir más con la poesía que con otras cosas. A mí me interesa la poesía como medio, como se dice en inglés, "mass médium”. Me parece que su impacto es más profundo que el del periódico, o de la radio o la televisión" (Borgeson, 1979, p. 378). A Cardenal le interesa la poesía en sí misma como un medio de comunicación perdurable, reflexiva, de hechura cuidadosa, cuya rigurosidad del contenido respecto a la vida sea verídica.

En Salmos la verdad vitaliza, la mentira menoscaba; el lenguaje abstracto y su mensaje son efímeros; y el lenguaje poético concreto y su mensaje son perpetuos. En el primer Salmo se lee: "Bienaventurado el hombre que no lee los anuncios comerciales/ ni escucha sus radios/ ni cree en sus slogans/ Será como un árbol plantado junto a una fuente” (Cardenal, 1969, p. 9). Una fuente es un manantial de agua, un lugar de donde este líquido nace o brota continua y abundantemente. Un árbol junto a una fuente crece y se mantiene firme. En estos versos, la fuente de agua es una figuración de la verdad (conocimiento), no contaminada, o la exactitud del lenguaje, antítesis de la propaganda. La verdad, como la fuente de agua, permite a las personas desarrollarse y crecer, como un árbol junto a un manantial. La verdad persiste en el tiempo, permanece continuamente como una fuente que brota inagotablemente. Quienes permanecen atentos a la verdad y evitan leer, escuchar, y principalmente creer en las mentiras que se difunden mediante los medios masivos de comunicación, no serán confundidos. Esta es la manera en que los individuos pueden alcanzar una libertad mental y de voluntad. Un discurso con un contenido falso puede ser propagado masivamente, pero en última instancia es siempre circunstancial. Así como los discursos falsos no permanecen, las obras que son producto de la mentira, basadas en la propaganda y el eslogan, están destinadas a perecer. Esta es una manera en que Cardenal ve posible una liberación física de la explotación al ser humano. Pues un árbol junto a una fuente permanece; pero un árbol que no absorba este líquido inevitablemente perece.

En otros poemarios, Cardenal ha mencionado la importancia de no descuidar la precisión de las palabras en sus versos debido a la elaboración atenta que tiene la propaganda política al componer su mensaje. Cardenal ha dicho en Epigramas: "Por eso los poetas pulimos tanto un poema" (1972a, p. 55). En la "Epístola a José Coronel Urtecho" (1978) Cardenal se refiere al lenguaje del discurso del poder financiero: "A los bancos les interesa que el lenguaje sea confuso/ ... / de ahí que nuestro papel sea clarificar el lenguaje./ Revaluar las palabras para el nuevo país" (p. 276). La poética exteriorista implica asumir una responsabilidad con el lenguaje y la sociedad. Por esto, a partir de una conciencia histórica, Cardenal efectúa su oficio puliendo el lenguaje para advertir al pueblo sobre los discursos engañosos del poder. Fuentes afirma que para Cardenal el lenguaje "es necesario como herramienta de trabajo y arma de lucha; en el fondo, para no sucumbir frente al poder destructor de quienes manejan las palabras con intenciones contrarias" (2004, p. 80). Para lo cual, "la opción de Cardenal es oponer una palabra desnuda de artificios y adornos" (Fuentes, 2004, p. 80).

Para lograr una sociedad distinta y más justa, se requiere usar las palabras con mayor exactitud, emplear términos que apunten a significados concretos de la realidad de manera 
sencilla, pero precisa. Esto supone una transformación en las personas, un cambio en el modo en que utilizan el lenguaje. Se necesita rechazar el lenguaje de los discursos del poder; se debe evaluar el significado de las palabras y restablecer sus sentidos con los cuales se explica la realidad inmediata. Es indispensable renovar el lenguaje y en lo posible, volver a encaminar el verdadero sentido de las palabras para referir realidades concretas exentas de abstracción.

\section{Conclusión: ocaso del poder}

Salmos habla de la apariencia formulada por la propaganda política y comercial. El Salmo 113 sostiene: "Sus ídolos son líderes políticos y estrellas de cine /-figuras pintadas en cartelones/ arte comercial-/ Boca tienen y no hablan / Ojos tienen y no ven/ Oídos tienen y no oyen/ Narices tienen y no huelen/ Son ficciones de sus mentes/ Y puras abstracciones/ Semejantes a ellos son los que los hacen/ y los que confían en ellos" (Cardenal, 1969, p. 57). Y la imagen momentánea y artificial de la fama que proyectan los medios de comunicación finalmente es desechada como el heno de los campos, el cual es separado de los productos substanciales de la tierra. Por esto el Salmo 36 dice que los nombres de los millonarios y los famosos "no estarán en ningún diario/ y ni los eruditos conocerán sus nombres/ Porque pronto serán segados como el heno de los campos" (Cardenal, 1969, p. 39). ${ }^{10}$

De manera semejante, Salmos declara el ocaso de las tiranías. A pesar de que la imagen de un dictador aparezca dilatada ante la opinión pública debido a la propaganda distribuida de su retrato, Cardenal augura que aún el nombre del dictador dejará de ser pronunciado, y concluye: "¿Y ahora quién los mienta?/ Fueron derribadas sus estatuas de bronce/ Las placas de bronce fueron arrancadas" (Cardenal, 1969, pp. 45-46). En "Sus acciones son como el heno de los campos" Cardenal presagia el fin de las potencias e imperialismos: "pronto caerán del poder/ Las armas que ellos fabrican se volverán contra ellos/ Sus sistemas políticos serán borrados de la tierra/ y ya no existirán sus partidos políticos/ De nada valdrán los planos de sus técnicos/ Las grandes potencias/ son como la flor de los prados/ Los imperialismos/ son como el humo" (Cardenal, 1969, p. 40). A través de figuraciones concretas que refieren a la naturaleza, Cardenal señala que las grandes potencias afloran solo durante una temporada; y los imperialismos se elevan y expanden grises como el humo que finalmente se disipa.

De la obra poética de Cardenal se ha dicho que tiene una "una interpretación negativa y apocalíptica de la sociedad contemporánea" (Daydí-Toson, 2000, p. 75). Pero cabe recordar que Salmos refiere a la catástrofe propiciada por las Guerras Mundiales y a la posibilidad de un conflicto nuclear durante la Guerra Fría. De esta manera, Cardenal continúa con la tradición intelectual hispanoamericana crítica a la contradicción del desarrollo científico europeo y la crisis bélicas del siglo XX. Si bien existen en Salmos expresiones de esperanza mesiánica donde la salvación se realizará por intervención directa de Dios, la esperanza de Cardenal en Salmos se basa también en la liberación del individuo mediante el uso responsable del lenguaje y el cambio de los hábitos de la vida moderna. No obstante Cardenal habla del sufrimiento de los pueblos, Salmos no está dominado por la fatalidad y el determinismo, al contrario, existe esperanza de liberación y consuelo mediante el rechazo a la propaganda de los discursos del poder y el análisis del lenguaje que contiene. Examinar el lenguaje del discurso político y comercial que instituyen prácticas sociales modernas: es decir, una conducta diferente. Por esto, Cardenal contrapone a la ambigüedad de la propaganda, la objetividad de la poesía exteriorista. 


\section{Notas}

1. En un artículo de 1969, Fernández Retamar explica el estado de la poesía hispanoamericana, manifestada en una generación de poetas con dos vertientes: la antipoesía y la poesía conversacional (1995, p. 159). Identifica a Ernesto Cardenal como "la más importante figura de la poesía conversacional" (1995, p. 161). Nombra además algunos títulos relacionados a esta generación de poetas: Poemas y antipoemas (1954) de Nicanor Parra (Chile, 1914-2018), Poemas de oficina (1956) de Mario Benedetti (Uruguay, 1920-2009) y Hora 0 (1960) y Gethsemaní (1961) de Ernesto Cardenal. También menciona a Samuel Feijoo (Cuba, 1914-1992) y Jaime Sabines (México, 1926-1999).

2. Según Benveniste, la enunciación introduce a su enunciador y descubre su instancia discursiva. Esta instancia de la enunciación es el sincretismo de tres factores: yo - aquí - ahora: 1) Yo-persona: "Está primero la emergencia de los indicios de persona (la relación yo-tú), que no se produce más que en la enunciación y por ella: el término yo denota al individuo que profiere la enunciación, el término tú, al individuo que está presente como alocutario" (1999, p. 85). 2) Aquí-lugar: Indicio de la ostensión (este, aquí, etc.), "términos que implican un gesto que designa el objeto al mismo tiempo que es pronunciada la instancia del término" (1999, p. 85). 3) Ahora-tiempo: "el 'presente', coincide con el momento de la enunciación" ya que "el hombre no dispone de ningún otro medio de vivir el 'ahora" (1999, pp. 85-86).

3. Los campos de concentración nazis tuvieron una gran extensión, se instalaban primeramente los edificios que alojaban a la SS, y los prisioneros habitaban barracas. El sector de los prisioneros tenía extensas alambradas de espino (Kogon, 2005, pp. 86-87).

4. El Estado SS tuvo también un programa de control y exterminio de personas enfermas de tuberculosis ya sea a través de inyecciones o las cámaras de gas (Kogon, 2005, p. 335).

5. Según Fernández Retamar, Occidente son aquellos países que "conocieron un pleno desarrollo capitalista” (1978, p. 9). Y afirma: "nuestra América está uncida, desde la arrancada misma del capitalismo, al mundo occidental, a cuyo desarrollo contribuyó decisivamente la rapaz y múltiple explotación (colonial primero y neocolonial después) que nuestros países, en su gran mayoría, no han dejado aún de padecer" (1978, p. 10).

6. Los postulados de Adolf Hitler y Joseph Goebbels con respecto a la propaganda fueron esenciales para manipular a la población alemana (Corella Torres, 2005, p. 25). En palabras de Goebbels, la propaganda fue útil para conquistar el Estado, crear uno nuevo y mantener el poder (citado en Corella Torres, 2005, pp. 10-11).

7. En la retórica publicitaria abundan las figuras de repetición y redundancia como el "paralelismo, el quiasmo y la recursividad" (Díez Arroyo, 1998, p. 100). Los medios de comunicación poseen "sofisticados canales" controlados por emisores especializados (Díez Arroyo, 1998, pp. 48 y 54).

8. Cardenal ha dicho: "Toda obra de arte es también una alabanza a Dios. Y da gloria a Dios, como las estrellas que proclaman la gloria de Dios. Todo verdadero arte es también en cierto sentido una oración" (1970, p. 117).

9. En 1949 Coronel Urtecho (Nicaragua, 1906-1994) publicó la antología Panorama y antología de la poesía norteamericana. Después, publicó junto a Ernesto Cardenal otras ediciones aumentadas de aquella antología (Cardenal, 2008, p. 10). Debido a este trabajo de traducción surgió el término "exteriorismo", la tendencia predominante de la poesía nicaragüense (Cardenal, 2008, p. 13). En una entrevista, Ernesto Cardenal asegura que Coronel Urtecho fue el responsable de llamar a esta adaptación "exteriorismo" (Ovalles, 1964, p. 14). Y ha declarado que con el tiempo su poesía fue "cada vez más exteriorista" (Ovalles, 1964, p. 14). Cardenal nunca ha usado el término conversacional para referirse a su poesía, sino que la ha llamado poesía "exteriorista". El coloquialismo en la poesía hispanoamericana se denomina "Exteriorismo" en Nicaragua (Valle-Castillo, 2010, pp. 52-53). Es importante recalcar que el exteriorismo aparece dentro de un "momento crucial y preciso en la historia de América Latina: la Revolución Cubana y, concomitantemente, la fundación del FSLN por Carlos Fonseca Amador" (Uriarte, 2000, p. 151).

10. Cardenal ha reflexionado en otros poemarios de lo efímero del poder y de los hábitos de la vida moderna. Por ejemplo, en "Somoza desveliza la estatua de Somoza en el Estadio Somoza" de Epigramas habla del eclipse del poder de Somoza, pues al hablar de la estatua que mandó a erguirla dice: "yo sé que el 
pueblo la derribará un día" (1972a, p. 45). En Gethsemaní, Ky, mediante imágenes que representan lo fugaz, Cardenal comenta de la brevedad de la vida moderna en su juventud - hábitos sociales, objetos tecnológicos, moda, belleza - sentenciando: "Y no ha quedado nada de aquellos días, nada" (1965, p. 24).

\section{Bibliografía}

Benveniste, É. (1999). Problemas de lingüística general. México: Siglo Veintiuno Editores.

Bihler, H. (2010). Los Salmos de Ernesto Cardenal en su relación con los salmos bíblicos. Un análisis comparativo de textos. En J. Valle-Castillo (Coord.). Re-visiones de Ernesto Cardenal. (pp. 193-228). Managua, Nicaragua: ANE Noruega.

Borgeson, P. W. (1979). Entrevista con Ernesto Cardenal. Hispania. 62, 377-379.

Borgeson, P. W. (1984). Hacia el hombre nuevo: Poesía y pensamiento de Ernesto Cardenal. London: Tamesis Books.

Cardenal, E. (1965). Gethsemani, Ky. Medellín, Colombia: Ediciones La Tertulia.

Cardenal, E. (1969). Salmos. Buenos Aires: Ediciones C. Lohlé.

Cardenal, E. (1970). Vida en el amor. Buenos Aires: Ediciones C. Lohlé.

Cardenal, E. (1971). El estrecho dudoso. Centroamérica: EDUCA.

Cardenal, E. (1972a). Epigramas. Buenos Aires: C. Lohlé.

Cardenal, E. (1972b). Homenaje a los indios americanos. Buenos Aires: Ediciones Carlos Lohlé.

Cardenal, E. (1975). Poesía nicaragüense. Managua: Ediciones el Pez y la Serpiente.

Cardenal, E. (1978). Nueva antología poética. México: Siglo Veintiuno Editores.

Cardenal, E. (2008). Presentando la poesía gringa. Casa de las Américas. 250, 11-19.

Chen Sham, J. (2007). La expresión hímnica en el psalterio: El caso de Ernesto Cardenal. Revista de Filología y Lingüística de la Universidad de Costa Rica. 33 (1), 21-32.

Chen Sham, J. (2016). Poesía y Música: correspondencias y despliegue expresivo en la poesía nicaragüense del siglo XX: Pallais, Cardenal y Téllez. Revista Pensamiento Actual. 6 (27), 125-139.

Corella Torres, N. (2005). Propaganda Nazi. Mexicali: Universidad Autónoma de Baja California.

Cornejo Polar, A. (1990). La problematización del sujeto en la poesía conversacional. En K. McDuffie y R. Minc (Eds.). Homenaje a Alfredo A. Roggiano. (pp. 201-207). Pittsburgh, Pa.: Instituto Internacional de Literatura Iberoamericana.

Coronel Urtecho, J. (1949). Panorama y antología de la poesía norteamericana. Madrid: Seminario de problemas Hispanoamericanos.

Daly de Troconis, Y. (1982). Los salmos de Ernesto Cardenal como propuesta de un nuevo código cristiano revolucionario. Caracas, Venezuela: Centro de Estudios Latinoamericanos Rómulo Gallegos.

Dapaz Strout, L. (1975). Nuevos cantos de vida y esperanza: Los Salmos de Ernesto Cardenal y la nueva ética. En J. Promis Ojeda (Ed.). (pp. 109-131). Ernesto Cardenal: Poeta de la liberación latinoamericana. Buenos Aires: F. García Cambeiro. 
Daydí-Toson, S. (2000). Revolución y apocalipsis: El milenarismo utópico de Ernesto Cardenal. En R. Cánovas y H. Hozven (Eds.). Crisis, apocalipsis y utopías. (pp. 75-78). Santiago de Chile: Instituto de Letras. Pontificia Universidad Católica de Chile.

Díez Arroyo, M. (1998). La retórica del mensaje publicitario: Un estudio de la publicidad inglesa. Oviedo: Universidad de Oviedo. Servicio de Publicaciones.

Durán, L. J. (2010). Bartolomé de las Casas y Ernesto Cardenal. En J. Valle-Castillo (Coord.). Re-visiones de Ernesto Cardenal. (pp. 193-228). Managua, Nicaragua: ANE Noruega.

Fernández Retamar, R. (1978). Nuestra América y el Occidente. México: UNAM.

Fernández Retamar, R. (1995). Para una teoría de la literatura hispanoamericana. Santafé de Bogotá: Caro y Cuervo.

Fuentes, M. E. (2004). La autenticidad de la palabra en busca de la palabra: Gethsemaní, Ky de Ernesto Cardenal. Taller de Letras. 34, 75-84.

Henighan, S. (2016). Sandino's Nation: Ernesto Cardenal and Sergio Ramírez Writing Nicaragua, 1940-2012. Montreal: McGill-Queen's University.

Kogon, E. (2005). El estado de la SS: el sistema de los campos de concentración alemanes. (E. Gimbernat, tr.). Barcelona: Alba Editorial.

Lasswell, H. D. (2015). Propaganda Technique in the World War. Greenville: Coachwhip Publications.

Lastra, P. (1987). Relecturas hispanoamericanas. Santiago: Editorial Universitaria.

Lee, S. J. (2004). The Colonial Legacy in Ernesto Cardenal's Poetry: Images of Quetzalcoatl, Nezahualcoyotl, and the Aztecs. Hispania. 87 (1), 22-31.

Mañú Iragui, J. (1990). Ernesto Cardenal: Vida y poesía. Caracas, Venezuela: Universidad Simón Bolívar.

Ovalles, C. (1964). Entrevista con Ernesto Cardenal. Col. 34, 14-15.

Picón-Salas, M. (1947). Europa-América: Preguntas a la Esfinge de la Cultura. México: Cuadernos Americanos.

Picón-Salas, M. (1962). Los malos salvajes: Civilización y pólitica contemporáneas. Buenos Aires: Editorial Sudamericana.

Pizarroso Quintero, A. (1993). Historia de la propaganda: Notas para un estudio de la propaganda política y de guerra. Madrid: EUDEMA.

Reinaga, F. (1978). La razón y el indio. La Paz: Litografías e Imprentas Unidas.

Rivera-Rodas, Ó. (2010). Historicidad y cosmopolitismo en la literatura hispanoamericana. Cuadernos americanos. 24 (1), 11-46.

Shaw, D. L. (2008). Spanish American Poetry After 1950: Beyond the Vanguard. Woodbridge, UK: Tamesis.

Uriarte, I. (2000). La poesía de Ernesto Cardenal en el proceso social Centroamericano. Managua: Centro Nicaragüense de Escritores.

Valle-Castillo, J. (2010). Calas en Ernesto Cardenal. En J. Valle-Castillo (Coord.). Re-visiones de Ernesto Cardenal. (pp. 15-68). Managua, Nicaragua: ANE Noruega. 
Veiravd, A. (1975). El Exteriorismo, poesía del nuevo mundo. En J. Promis Ojeda y E. Calabrese (Eds.). Ernesto Cardenal: Poeta de la liberación latinoamericana. (pp. 62-106). Buenos Aires: F. García Cambeiro.

Zea, L. (1955). América en la conciencia de Europa. México: Los Presentes.

Zea, L. (1957). América en la historia. México: FCE. 
